\title{
Verification of forecasts of periodic changes in the climate of Warsaw in the period 1779-2010
}

\begin{abstract}
The air temperatures recorded at Warsaw-Okęcie in 1951-2010 were compared with forecasts for the period 1980-2010 and 1991-2010, i.e. 31 and 20 years ahead. Accurate predictions of air temperatures in Warsaw in 1980-2010 were calculated using the cycles identified by applying the sinusoidal regression method to a series of monitoring results obtained in Warsaw between 1779 and 1979. The high accuracy of these forecasts is the result of a similar progression of measured and forecast values over a number of years. The prediction of climate change in the Northern Hemisphere for example, caused by interference of long solar radiation cycles as well as variations in the concentrations of the $\delta^{18} \mathrm{O}$ oxygen isotope in the Arctic ice cores, requires a larger series of data points.
\end{abstract}

Keywords

Air temperature $\bullet$ Wolf numbers $\bullet$ period $\bullet$ interference $\bullet$ forecast $\bullet$ tree ring

(C) University of Warsaw - Faculty of Geography and Regional Studies

\author{
Jerzy Boryczka \\ Maria Stopa-Boryczka² \\ Urszula Kossowska-Cezak ${ }^{3}$ \\ Jolanta Wawer ${ }^{4}$ \\ ${ }^{1}$ Institute of Physical Geography, \\ Faculty of Geography and Regional Studies, \\ University of Warsaw \\ e-mail: jkborycz@uw.edu.pl \\ 2Institute of Physical Geography \\ Faculty of Geography and Regional Studies, \\ University of Warsaw \\ Received: 27 March 2012 \\ Accepted: 27 September 2012
}

\author{
${ }^{3}$ Institute of Physical Geography, \\ Faculty of Geography and Regional Studies, \\ University of Warsaw \\ ${ }^{4}$ Institute of Physical Geography, \\ Faculty of Geography and Regional Studies, \\ University of Warsaw \\ e-mail: jgwawer@uw.edu.pl
}

Introduction

The aim of this paper is the verification of the climate forecasts developed in a number of studies conducted at the Department of Climatology of the University of Warsaw (by Boryczka et al.) on the basis of the longest available observation series from Warsaw, i.e. from 1779 onwards. It is an assessment of the synchronicity between the measured and predicted air temperatures at Warsaw-Okęcie for a 31-year period between 1980 and 2010, and a 20-year period between 1991 and 2010.

A considerable advance in the study of climate change was the identification of the causes of natural cooling and warming of the climate from the 18th century up until the present day. By using the sinusoidal regression method originally developed by Boryczka (1998), it was also possible to study the periodicity of phenomena occurring at various time intervals (e.g. volcanic eruptions, sediment layers). An analogous cyclicity of climatological, dendrological and sedimentological $\left(\delta^{18} \mathrm{O}\right.$ oxygen isotope in the ice core and organic substances in lacustrine deposits) variables was demonstrated, as well as of astronomical and geological variables, i.e. the presumed underlying causes. The identification principle, defined as "the periods of effects and causes are similar, and fluctuations - synchronous", should be fulfilled. The dominant roles of solar activity and volcanic eruptions in the changes of the Earth's climate were demonstrated.

The approximately comparable cyclicity of these variables

made it possible to reconstruct and forecast changes in the European climate in the 21 st century, primarily air temperature and the width of tree rings. Furthermore, forecasts of climate change in the Northern Hemisphere during the next 100,000 years based on changes in solar radiation near the upper edge of the atmosphere $\left(\varphi=65^{\circ} \mathrm{N}\right)$ and periodic oscillation of the oxygen $\delta^{18} \mathrm{O}$ isotope contained in the ice core, are also quite interesting (Boryczka et al. 2010).

Determining the period of change relating to solar activity, air temperature and tree rings is essential in explaining the natural causes underpinning climate fluctuations. For temperature trend forecasts, it was assumed that the short and long periods identified in the measurement series would continue to recur. This assumption is justified by the analogous solar activity periods (solar constant) that underpin periodic climate changes.

Cycles, i.e. $\Theta$ periods, amplitudes $b$ and phases $c$ were determined using the sinusoidal regression method, by modifying the period of sinusoidal periods $\Theta$ to a time interval of 0.1 year:

$y=a_{\mathrm{o}}+b \sin \left(\frac{2 \pi}{\Theta} t+c\right)$

The forecasts and reconstructions of air temperature are affected by random interferences with a cycle of $k$ : 
$y=f(t)=a_{\mathrm{o}}+a t+\sum_{\mathrm{j}=1}^{\mathrm{k}} b_{\mathrm{j}} \sin \left(\frac{2 \pi}{\Theta_{\mathrm{j}}} t+c_{\mathrm{j}}\right)$

where: $t=$ time, and $a t=$ linear component.

The number of the periods and their lengths was determined so as to ensure that the standard error for the time trend $f(\mathrm{t})$ was minimised. Therefore, the extrapolated values (reconstructed $(t<0)$ and predicted $(t>n))$ have a high degree of reliability.

Impact of solar activity on climate

Changes in solar activity from 1700 to 2010 were determined on the basis of the annual Wolf numbers in the period 1700-1748 (Reznikov 1982) and the average monthly Wolf numbers in the period 1749-2010 (Royal Observatory of Belgium 2011).

The periods $\Theta_{j}$, amplitudes $b_{j}$ and phases $c_{j}$ of the cycles identified between 1749 and 2010 (and *1700-2010), the correlation coefficient $\mathrm{R}$ and the Fobl (F-test) are given in Table 1 (below).

Table 1. Periods $\Theta$, amplitudes $\mathrm{b}$ and phases $\mathrm{c}$ of Wolf number cycles in the years $1749-2010\left(^{*} 1700-2010\right)$

\begin{tabular}{|c|c|c|c|c|}
\hline$\Theta$ & $b$ & $c$ & $R$ & $F_{\text {obl }}$ \\
\hline 8.5 & 11.02 & 0.2389 & 0.189 & 4.775 \\
\hline 10.0 & 24.158 & 2.3963 & 0.399 & 24.451 \\
\hline 11.0 & 30.237 & 1.0218 & 0.500 & 43.089 \\
\hline 11.8 & 17.859 & -2.6703 & 0.273 & 10.399 \\
\hline 14.1 & 6.411 & 1.9267 & 0.142 & 2.654 \\
\hline 21.2 & 7.001 & -0.4033 & 0.133 & 2.336 \\
\hline 30.1 & 4.572 & 1.6251 & 0.098 & 1.254 \\
\hline 41.1 & 7.131 & -1.5085 & 0.158 & 3.299 \\
\hline 51.8 & 8.819 & -1.4532 & 0.170 & 3.865 \\
\hline 66.4 & 7.792 & 2.6537 & 0.164 & 3.580 \\
\hline 103.3 & 16.334 & 1.6550 & 0.279 & 10.972 \\
\hline$* 184.1$ & 7.398 & -2.7499 & 0.217 & 7.589 \\
\hline
\end{tabular}

The 11 year solar activity cycle, with a maximum amplitude $b=$ $30.237(R=0.500)$, plays the most important role in determining climate, while the longest cycles, 103.3 years and 184.1 years with amplitudes $b=16.334(R=0.279)$ and $b=7.398(R=0.217)$ respectively, are also statistically significant (at a level of $<0.05$ ). The interference of the major solar activity cycles (Table 1) with a linear coefficient 108.276943+0.0837769 t (multiple correlation coefficient $R=0.876$ ) for the period $1600-2100$ is shown in Fig. 1 . Solar activity between 1700 and 2010 shows an increasing trend of 9.19 per 100 years.

There are many similarities between the changes in annual average air temperatures in Warsaw and Wolf numbers in the period 1951-2010 (see Fig. 2). The synchronicity of air temperature changes in Warsaw and Wolf numbers over many years suggests that solar activity is one of the main factors that drives climate change.

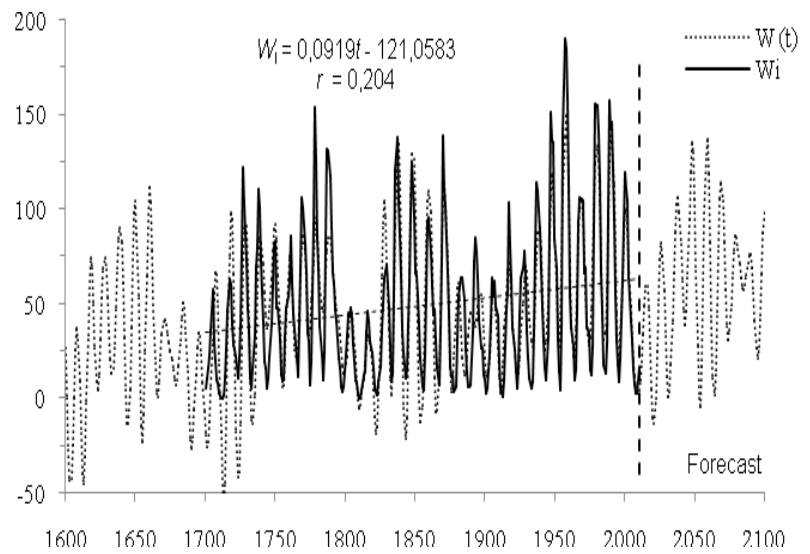

Fig 1. Changes in solar activity (Wi - Wolf number) between 1600 and 2100 , with a reconstruction for the period 1600 1748 and a forecast for 2011-2100
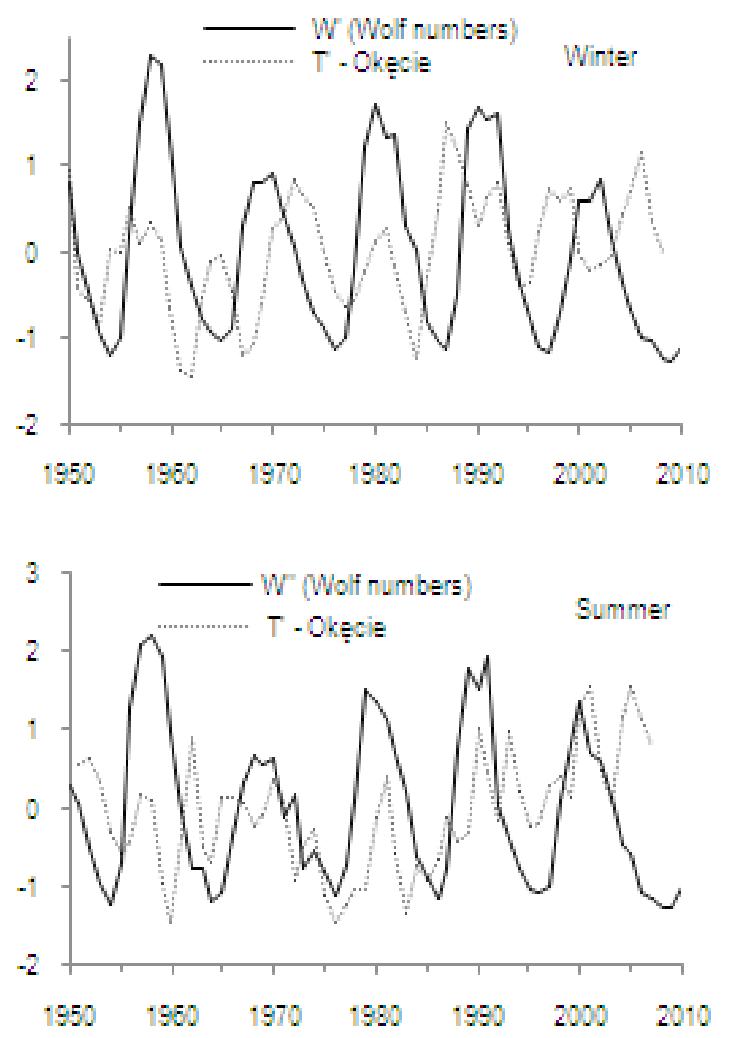

Fig 2. Changes to the standardised Wolf numbers ( $\left.W^{\prime}\right)$ and air temperature values at Warsaw-Okęcie ( $T^{\prime}$ - average of 3 consecutive years) in winter and summer (1951-2010)

The average tree ring widths of five trees growing in Europe are correlated with the Wolf numbers for 1700-2010. These trees are: Pinus silvestris (Forfjorddalen, Norway, 1877-1994); Picea abies (Falkenstein, Germany, 1540-1995, Fodara Vedla, Italy, 1598-1990 and Stonnglandes, Norway, 1403-1997) and Larix decidua (Pinega, Russia, 1578-1990), with a correlation coefficient $r=0.236>r_{0.05}$ (according to the t-Student test) (Fig. 3). 


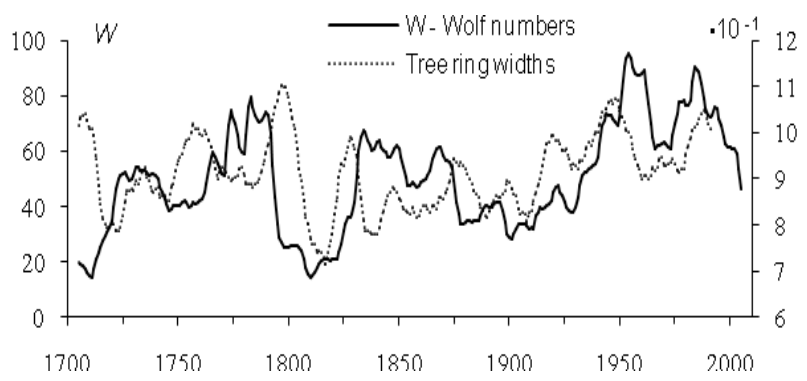

Fig 3. Synchronous fluctuations in the average tree ring width of 5 trees in Europe and Wolf numbers from 1700-2010 (average of 11 consecutive years)

Air temperature changes in Warsaw-Okęcie from 1951 to 2010, most notably in winter, were dependent on the North Atlantic Oscillation (Fig. 4). This is confirmed by a high correlation coefficient $(r=0.705)$ for temperature $\mathrm{T}$ and the NAO Index (critical value $r_{0.05}=0.255$ ).

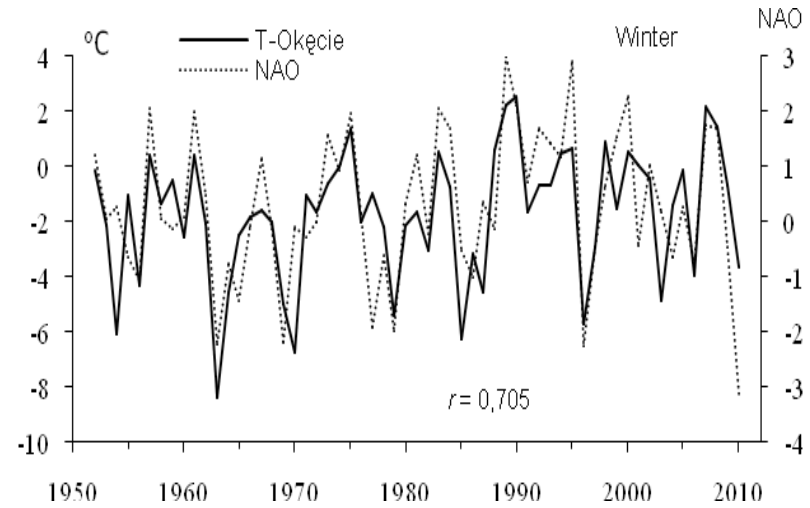

Fig 4. Air temperature changes in Warsaw-Okęcie and winter NAO levels in 1951-2010

Impact of volcanic eruptions on climate

Periodic volcanic episodes also cause changes in the amount of direct and diffuse sunlight reaching the Earth's surface.

The content of volcanic dust in the atmosphere was measured using the Dust Veil Index (DVI) (Lamb 1974) in the years 1680-1980. The periods of this (discontinuous) variable could only be determined using the sinusoidal regression method (see Table 2).

Table 2. Periods $\Theta$, amplitudes $\mathrm{b}$ and phases $\mathrm{c}$ of numerical cycles of the log DVI index in the years 1680-1980

\begin{tabular}{|c|c|c|c|c|}
\hline$\Theta$ & $b$ & $c$ & $R$ & $F_{\text {obl }}$ \\
\hline 4.0 & 0.1627 & -3.0401 & 0.339 & 4.15 \\
\hline 5.3 & 0.1076 & -1.1978 & 0.362 & 4.83 \\
\hline 8.6 & 0.0515 & 1.2260 & 0.287 & 2.87 \\
\hline 11.4 & 0.1825 & -2.5887 & 0.314 & 3.50 \\
\hline 13.2 & 0.0200 & -0.6048 & 0.287 & 2.87 \\
\hline 16.4 & 0.0685 & -0.9181 & 0.257 & 2.27 \\
\hline 30.8 & 0.0820 & 0.7333 & 0.205 & 1.40 \\
\hline 38.4 & 0.0694 & 0.4305 & 0.223 & 1.68 \\
\hline 91.8 & 0.1734 & 1.8603 & 0.339 & 4.15 \\
\hline 256.5 & 0.1555 & -3.1375 & 0.241 & 1.97 \\
\hline
\end{tabular}

The 11.4-year and 91.8-year cycles of the log DVI, which are similar to the known periods of solar activity, are of particular interest.

The interference of the cycles of the indicator $F(t)=\log D V I$ (Tab. 2) with a linear coefficient 2.690577- $0.00107 t$ (multiple correlation coefficient $R=0.719$ ) is shown in Fig. 5a. It should be noted that between 1600 and 2100, the value of log DVI decreases signifying a reduction in the concentration of volcanic dust in the atmosphere. The influence of volcanic eruptions on climate are also attested to by the variations in the width of tree rings, e.g. the Pinus sylvestris pine in Vikran (1599-1992) which is positively correlated with the - log DVI index and signifies the removal of volcanic dust from the atmosphere (see Fig. 5b) (Stopa-Boryczka et al. 2007).

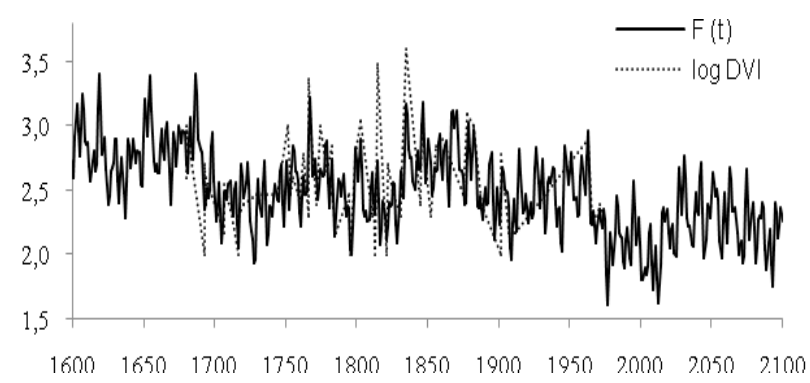

Fig 5a. Changes in log DVI (Dust Veil Index) between 1600 and 2100 according to the interference of the $F(t)$ cycle, with a forecast for 1975-2100 and measured values

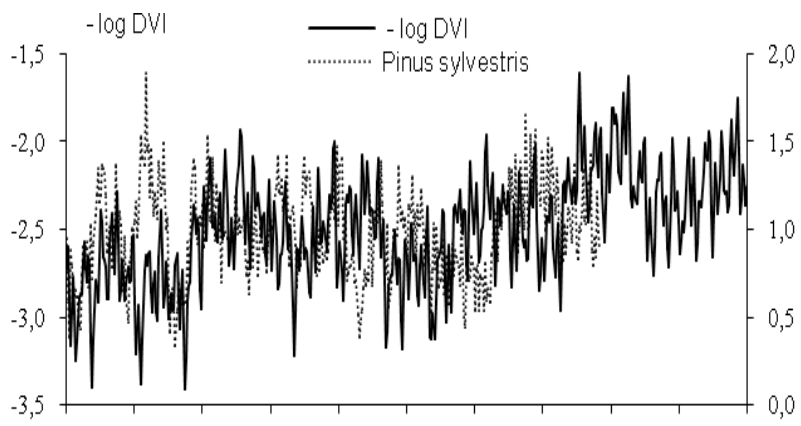

$\begin{array}{lllllllllll}1600 & 1650 & 1700 & 1750 & 1800 & 1850 & 1900 & 1950 & 2.000 & 2.050 & 2.100\end{array}$

Fig $5 b$. Changes in tree ring width for the Pinus sylvestris pine in Vikran (1599-1992) and the-logDVI index between 1600 and 2100

Accuracy of air temperature forecasts in Warsaw in 1984 based on measurements from 1779 to 1979

Air temperature trends in Warsaw between 1980 and 2100 based on data from 1779-1979 (Astronomical Observatory) were first compiled on the basis of the reconstruction and predictive model of air temperature changes over a number of years (Boryczka 1984). The model takes into consideration the interference of 6 cycles with periods of 1, 11.2, 22, 18.6, 90 and 220 years, and the modulation of the annual cycle with a frequency $\Omega_{1}=2 \pi$ by shorter cycles of 22,90 and 220 years:

$$
y=f(t)=7.467+11.45 \sin (2 \pi t-2.1290)+\sum_{\mathrm{j}=1}^{\mathrm{k}} b_{\mathrm{j}} \sin \left(\Omega_{\mathrm{j}} t+c_{\mathrm{j}}\right)
$$

The model is characterised by the high coefficient of determination 
$R^{2}=0.929$ and a small standard error $\delta=2.255^{\circ} \mathrm{C}$.

Temperature cycles are caused by the Earth's rotation around the sun, the 11-year solar cycle and 22-year solar magnetic field cycle, the precession and nutation of the earth and the 100- and 200-year cycles of solar activity.

In order to verify the forecasts based on this model, the average monthly air temperature values were calculated by entering the relevant period into the formula e.g. July $-t+0.5833$, where $t=0$ is 1778 .

Of particular importance is the synchronicity between changes in the values of air temperature in Warsaw between 15002500, calculated for July using the model $T=f(t)$ and the widths of oak tree rings (Quercus petraea) in Bodensee (The Netherlands, 1398-1993) (see Fig. 6). The widths of the tree rings on this oak are characteristic of the two strongest cycles that had a period of 112 and 197 years (correlation coefficient 0.248 and 0.373 ).

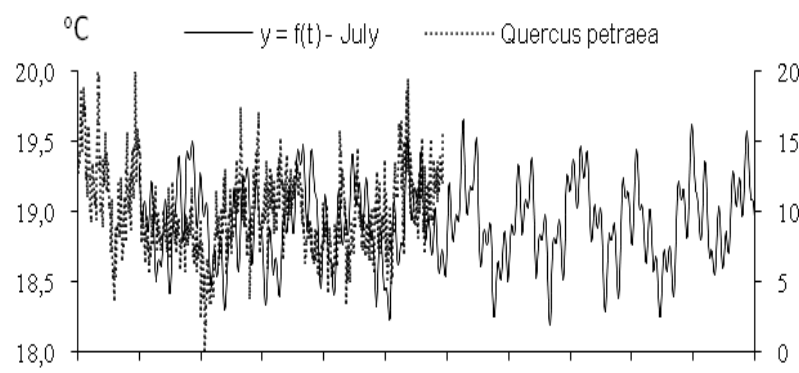

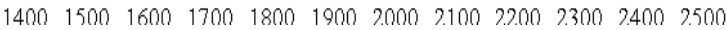

Fig 6. Changes in July air temperature between 1500 and 2500 (values obtained from the $y=f(t)$ model) relative to the tree ring width in Bodensee (Netherlands) between 1400 and 1993

The synchronicity of the changes also appears in the widths of the tree rings of this oak (1500 to 1993) and the moment of the planets of the solar system relative to the elliptical plane (Fig. 7).

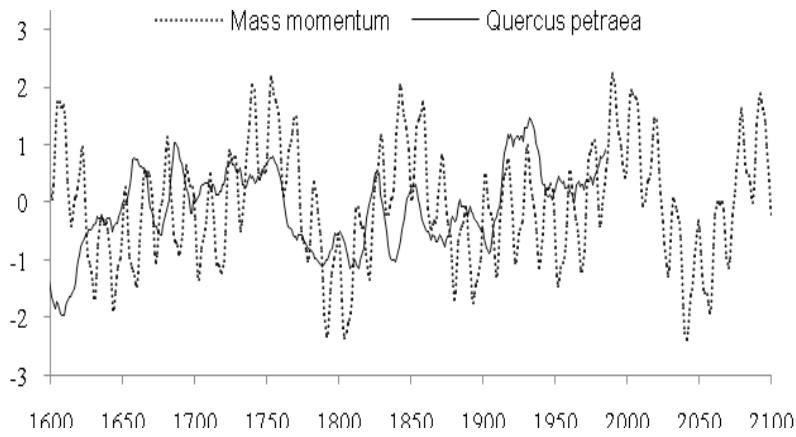

Fig 7. Changes to tree ring width (Quercus petraea) in Bodensee (standardised) in 1500 and 1993, relative to the moment of the planets in the solar system, $M_{z}$

Above all, the current verification of this model involves a comparison of the 30-year series of results of air temperature measurements (average values for consecutive 3-year periods in July) in Warsaw-Okęcie $(T)$ and the calculated values, $y=f(t)$, for the period between 1980 and 2010 (Fig. 8). Based on the measurements and forecasts, there is generally significant agreement between the air temperature maxima and minima in the 31-year period between 1980 and 2010. For example, in July the connection between the measured $\left(y^{\circ} \mathrm{C}\right)$ and forecast $\left(x^{\circ} \mathrm{C}\right)$ air temperatures at Okęcie are described by a simple regression with a correlation coefficient of $r=0.444$, and significance at a level of 0.05 (t-Student test, $r_{0.05}=0.349$ ) (Fig. 9).

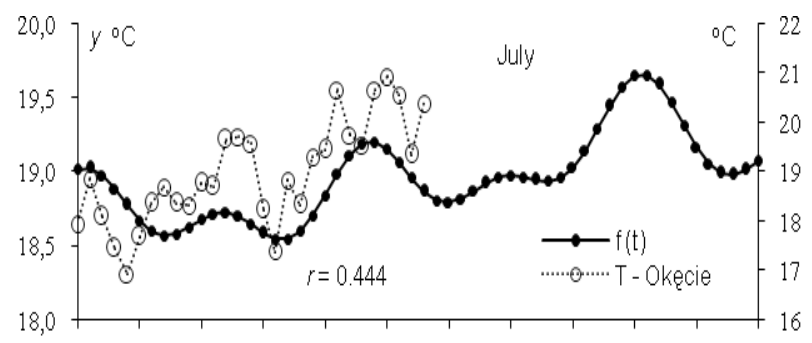

$\begin{array}{llllllllllll}1980 & 1985 & 1990 & 1995 & 2.000 & 2.005 & 2.010 & 2.015 & 2.020 & 2.02 .5 & 2.030 & 2.035\end{array}$

Fig 8. Comparison of measured air temperature values at Warsaw-Okecie (average of 3 consecutive years) with forecasts (1980-2035) according to the reconstructive and prognostic model $y=f(t)$

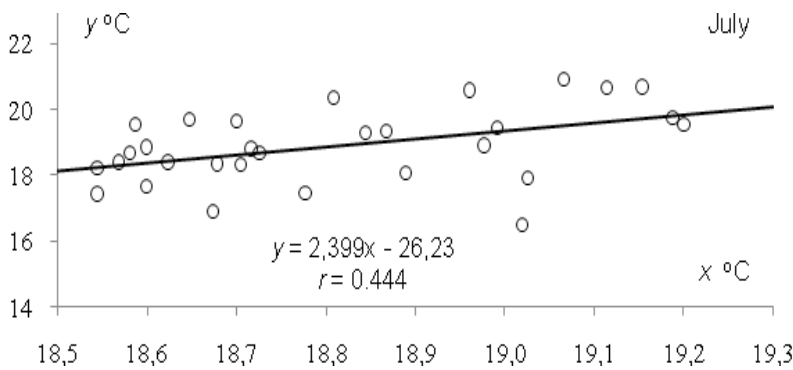

Fig 9. Correlation of the measured July air temperature values (average of 3 consecutive years) with those forecast $(x)$ for 30 years ahead (1980 to 2010)

Accuracy of air temperature forecasts in Warsaw based on measurements from the period 1779 to 1990

Forecasts concerning the air temperature trends in Warsaw for the years 1991-2100, made on the basis of the data of the Astronomical Observatory from the years 1779-1990 (Boryczka et al. 2000), proved the most reliable. As an example, the measured average air temperature values were compared at different time intervals (winter, January, summer) for Warsaw-Okęcie with those forecast for the years 1990-2035.

In winter, the trend of air temperature in Warsaw (the linear component $\mathrm{a}=0.01025) T=F(t)$ over time results from the overlapping of 12 cycles present in the air temperature spectrum, with the longest lasting 113.1 years and 218.3 years:

\footnotetext{
$T=F(t)=-3.721+0.01025 t+$

$+0.5218 \sin (2 \pi t / 2.6-1.332)+0.5674 \sin (2 \pi t / 3.5+0.5448)$ $+0.6281 \sin (2 \pi t / 5.2+0.06199)+$

$+0.4266 \sin (2 \pi t / 5.7+2.484)+0.7091 \sin (2 \pi t / 7.7-0.7349)$ $+0.7349 \sin (2 \Pi t / 8.3-2.368)+$

$+0.4920 \sin (2 \pi t / 8.7-0.3439)+0.4082 \sin (2 \pi t / 12.9+0.1191)$ $+0.4379 \sin (2 \Pi \mathrm{t} / 15.2+2.252)+$

$+0.4685 \sin (2 \pi t / 18.0-3.097)+0.5029 \sin (2 \pi t / 113.1+1.197)$ $+0.2097 \sin (2 \pi t / 218.3+2.497)$.
} 
The fluctuations in the measured air temperatures at Warsaw-Okęcie (averages of three consecutive years) and the forecast winter temperatures for 1991-2010 (according to the model $T=F(t)$ ) are generally synchronous (see Fig. 10). The linear component: $\mathrm{a}=1.025^{\circ} \mathrm{C} / 100$ years - warming in $1779-2100$ (see forecast of global warming in the 21 century, ENSEMBLE project http://www.ensembles-eu.org/).

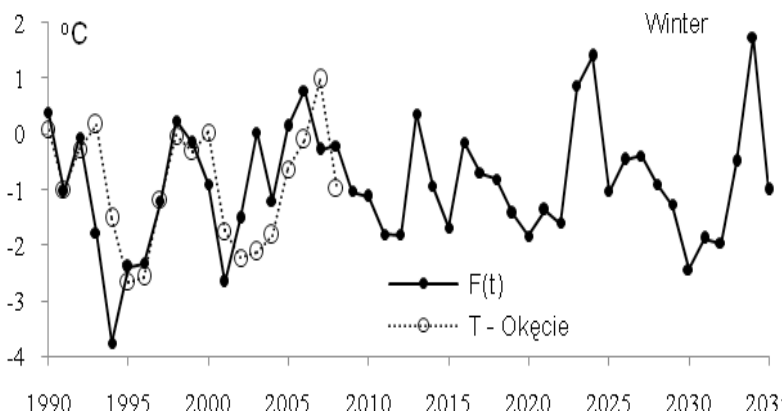

Fig 10. Changes in winter air temperatures in Warsaw in 19902035, as measured at Okęcie (average of 3 consecutive years), $T=F(t)$, forecast

The forecasts of January air temperatures for 1991 to 2035 (20 years ahead) were obtained on the basis of a time trend $T=f(t)$ which takes into account the interference of 12 cycles of 2.62, 3.5, 4.8, 6.6, 7.7, 9.3, 13.0, 15.4, 27.5, 62.5, 122.7, 204.8 years (Fig. 11).

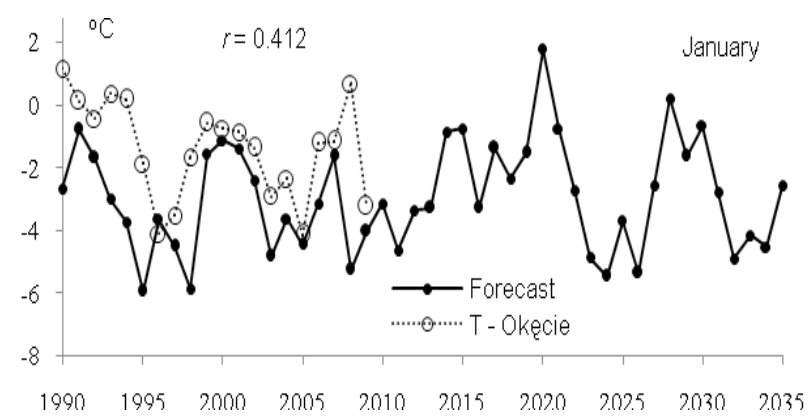

Fig 11. Changes in January air temperatures in Warsaw in 19902035, $T$ - measured temperatures (average of 3 consecutive years), $T=F(t)$, forecast

The agreement of the measured and forecast temperature $T_{\mathrm{i}}$ in Okęcie (average of 3 consecutive years) is demonstrated by the 20-year period considered and the correlation coefficient $r=0.412$ which is close to the critical value $r_{0.05}=0.423$ at a level of $5 \%$ and higher than $r_{0.10}=0.356$.

In summer, the time trend of air temperature in Warsaw $T=f(t)$ is a superposition of 12 cycles present in the spectrum of air temperature values (Astronomical Observatory) and the longest cycles: $3.9,4.7,5.2,6.5,7.1,7.4,7.8,15.9,22.5,44.3,91.2$ and 208.2 years.

In the decade 2001-2010, the accuracy of summer forecasts decreased compared to the decade of 1991-2000 (Fig. 12).

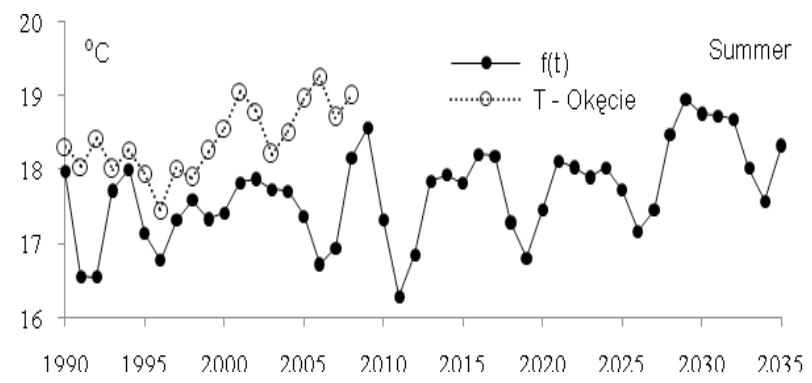

Fig 12. Changes in summer air temperatures in Warsaw in 19902035, T-measured temperatures at Okęcie (average of 3 consecutive years), $T=f(t)$, forecast

Urban heat island forecast for Warsaw

based on measurements between 1951 and 2000

The heat island effect in Warsaw was usually characterised as the difference of air temperature $\left(\Delta T=T_{m}-T_{o}>0\right)$ between the city $T_{m}$ (the city centre or the Astronomical Observatory) and its peripheries $T_{0}$ (Okęcie).

The difference in air temperature between the centre of Warsaw and its peripheries (1933-2000) depends on anthropogenic factors such as the expansion of the city and atmospheric circulation (Kossowska-Cezak 2002). For instance, in the 1960s a significant heat island effect was observed with SW circulation while in the 1970s, a weak heat island effect was observed with NE circulation. At that time, Okęcie was within range of the urban heat island effect.

The differences in air temperature $\Delta T$ between the city centre and periphery from 1960 to 1980 made it possible to estimate relative diurnal "heat resources" in the city centre (proportional to $\Delta \mathrm{T}$ ) (Stopa-Boryczka et al. 1995).

The trends concerning the urban heat island in Warsaw in the years 1951-2000, i.e. the differences in air temperatures between Bielany, the Astronomical Observatory and Okęcie and between Bielany and Legionowo were described in some publications (Kicińska, Wawer 2005). For example, the differences in the average annual air temperatures between Bielany and Okęcie are characterised by a regression coefficient of $0.00560^{\circ} \mathrm{C} /$ year, and those between the Astronomical Observatory and Okęcie - by $0.00462^{\circ} \mathrm{C} /$ year.

Air temperature in Warsaw (Astronomical Observatory and Okęcie) as well as the heat island (difference $\Delta T$ ) are characterised by periodic diurnal and annual courses of values which depend on the advection of air from the west - from the Atlantic Ocean (and NAO). Atmospheric circulation, mostly in winter, depends on the temperature of Atlantic waters (Marsz, ed.1999).

The differences in air temperature $(\Delta T)$ between the city centre and its peripheries in the years 1951-2000 are also characterised by multiannual periodicity (in winter - 2.4, 5.6, 6.9, 9.2, $11.5,16.3$ and 29.0 years and in summer - 2.9, 5.4, 7.9, 9.4, 12.0,16.8 and 29.2 years). 
Based on these cycles, a forecast of changes in the urban heat island in Warsaw was proposed (Stopa-Boryczka et al. 2011).

The interference of these cycles of air temperature differences $\Delta T$ was determined using the linear component at. Winter and summer air temperature differences $\Delta T$ between the city centre and its peripheries for 1920-2030, with a forecast for 2001-2030, are shown in Fig. 13.
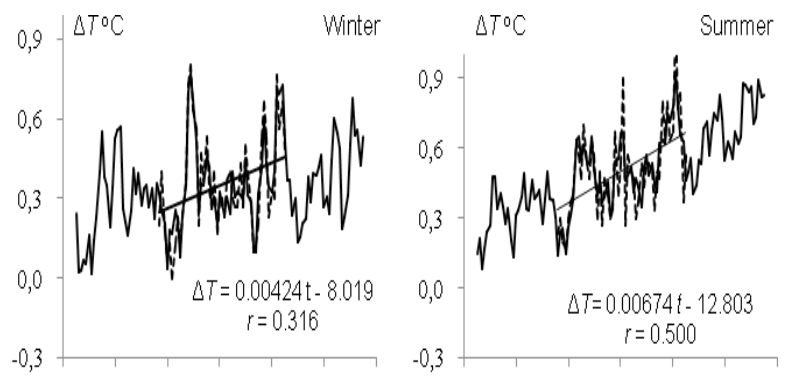

$191519351955197519952.0152 .035 \quad 191519351955197519952.0152 .035$

Fig 13. Changes in the differences $(\Delta T)$ in air temperature between the city centre (Astronomical Observatory) and the periphery (Okęcie) of Warsaw in winter and summer from 1920 to 2030

The trends concerning changes in air temperature differences $(\Delta T)$ between the centre of Warsaw (Astronomical Observatory) and the peripheries (Okęcie) in the years 19512000 were determined using simple regression equations which gave the following results: winter $-0.042^{\circ} \mathrm{C} /$ year, summer $0.067^{\circ} \mathrm{C} /$ year.

These upward trends concerning the urban heat island are affected by changes in atmospheric circulation, including the North Atlantic Oscillation, and are also due to the city's expansion after 1950 (an increasing number of artificial surfaces with low albedo).

\section{Conclusions}

1. The synchronicity between measured and forecast air temperature fluctuations in Warsaw-Okęcie for the years 1980-2035 and 1991-2035 (a 30- and 20-year period) and relevant statistical correlation coefficients (with $95 \%$ confidence level), corroborated the appropriateness of the selected research and forecasting methods (according to the interference cycle);

2. The verification of air temperature forecasts using Warsaw as an example, suggests that the temperature periods identified earlier (20 or 30 years ago) could be extrapolated beyond the approximation range (measurement range);

3 . The longest air temperatures cycles of over approximately $100-$ and 200-year periods, determined on the basis of a relatively short monitoring series (about 200 years) also proved reliable. They can be observed in the chronological sequences of the ring widths of certain trees growing in Europe as well as sedimentological variables, going back several hundred thousand or several thousand years;

4. An important problem that remains to be solved in the 21 st century is the identification of the natural causes of changes in the Earth's climate and specifically in Europe (and Poland). It involves the identification of some deterministic (periodic) components in the measurement series, as well as mechanisms whereby the impact of astronomical factors is transposed onto the Earth's climate; 5. The question of whether climate warming will continue or whether there will be a deep natural cooling caused by reduced solar activity (solar constant) and increased volcanic dust content in the atmosphere will probably be resolved in this century;

6. Verification of long-term climate change forecasts for the Northern Hemisphere, determined on the basis of very long cycles of solar radiation reaching the Earth's surface, oxygen $\delta^{18} \mathrm{O}$ isotope contained in the Arctic ice core and organic substances deposited in lakes, require longer measurement series (Boryczka et al. 2010).

\section{References}

Boryczka, J 1984, Model deterministyczno-stochastyczny wielookresowych zmian klimatu [Deterministic and stochastic model of multiperiodic climate changes], Wyd. UW, Warsaw

Boryczka, J 1998, Zmiany klimatu Ziemi [Changes of the Earth's climate], Wyd. Akadem. "Dialog", Warszawa

Boryczka, J, Stopa-Boryczka, M, Lorenc, H, Kicińska, B, Błażek, E, Skrzypczuk J 2000, Atlas współzależności parametrów meteorologicznych i geograficznych w Polsce [Atlas of correlations between meteorological and geographical parameters in Poland], vol. XIV, p. 209.

Boryczka, J, Stopa-Boryczka M, Unton-Pyziołek A, Gieszcz P 2010, 'Cooling and Warming of Climate of the Earth's Northern Hemisphere (on the basis of fluctuations of the oxygen isotope $\delta^{18} \mathrm{O}$ and dendrological data)', Miscellanea Geographica, vol. 14, pp. 47-58. Available from: <http://www.ensembles-eu.org/>

Kicińska, B, Wawer, J 2005, 'Urban climate 8. Weather and air conditions', in Urban sprawl Warsaw agglomeration case study, ed M Gutry-Korycka, Wyd. WGSR
Kossowska-Cezak, U 2002, 'Zmiany różnicy temperatury powietrza między śródmieściem a peryferiami Warszawy od 1933 do 2000 roku' [Changes in air temperature differences between the city centre and peripheries of Warsaw in the period 1933-2000], Przegląd Geofizyczny, vols. 3-4, pp. 203-209.

Lamb, HH 1974, 'Volcanic dust in the atmosphere witch a chronology and assessment of meteorological', Phil. Transactions Roy. Soc., vol. 226.

Marsz, AA (ed.) 1999, 'Wpływ stanu termicznego powierzchni oceanu na modyfikacje cyrkulacji atmosferycznej w wymiarze klimatologicznym' [Impact of the thermal condition of the ocean's surface on the modification of atmospheric condition in the climatological dimension]', Conference proceedings, Gdynia 6 May 1999.

Reznikov, AP 1982, Priedskazanije jestiestwiennych processow obuczajuszcziejsja sistiemoj [Forecasting of natural processes using a learning system], Novosibirsk

Royal Observatory of Belgium, 2011, http://sidc.oma.be/DATA/index.html Stopa-Boryczka, M, Boryczka, J, Błażek, E, Skrzypczuk, J 1995, Atlas 
współzależności parametrów meteorologicznych i geograficznych w Polsce [Atlas of correlations between meteorological and geographical parameters in Poland], vol. IX, pp. 320.

Stopa-Boryczka, M, Boryczka J 2003, 'The cyclic changes of the climate of Warsaw and their conditioning, Studies on the climate of Warsaw', in Studies on the climate of Warsaw, ed M Stopa-Boryczka, Warsaw, pp. 35-50.

Stopa-Boryczka, M, Boryczka, J, Bijak, Sz, Cebulski, R, Błażek, E,
Skrzypczuk, J 2007, Atlas współzależności parametrów meteorologicznych i geograficznych w Polsce [Atlas of correlations between meteorological and geographical parameters in Poland], vols. XX-XXI, p. 266.

Stopa-Boryczka, M, Boryczka, J, Wawer, J, Grabowska, K 2011, 'Badania klimatu w różnych skalach przestrzennych' [Climate studies in different spatial scales], Prace $i$ Studia Geograficzne, vol. 47 , pp. 409-416. 